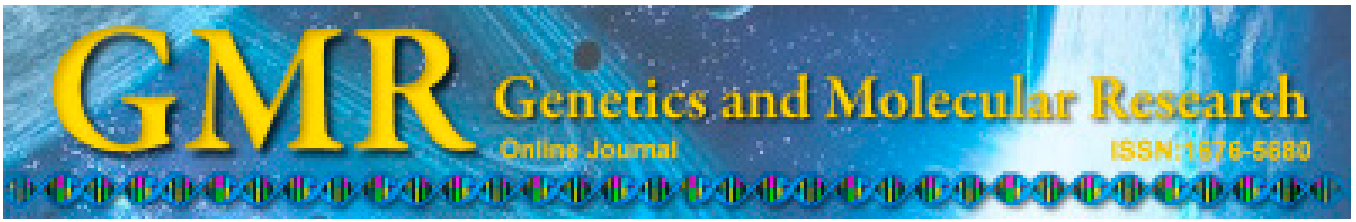

\title{
Phenotypic variation and diversity of Magnolia sprengeri Pamp. in native habitat
}

\author{
M. Yang, S.G. Shi, W. Liu, M. Zhang, L. Gou, Y.X. Kang and J.J. Liu \\ Northwest A\&F University, Yangling, Shaanxi, China \\ Corresponding author: J.J. Liu \\ E-mail: 1jj@nwsuaf.edu.cn
}

Genet. Mol. Res. 14 (2): 6495-6508 (2015)

Received February 10, 2015

Accepted May 29, 2015

Published June 12, 2015

DOI http://dx.doi.org/10.4238/2015.June.12.2

\begin{abstract}
The population of Magnolia sprengeri individuals deceased drastically in the late 20th century because of the widespread harvest for traditional Chinese medicinal recipes. In this study, the levels of phenotypic variation and the genetic structure of 2 populations of $M$. sprengeri were estimated. The phenotypic variation of $M$. sprengeri characteristics was nonsynchronous, with a coefficient of variation for 37 characters from $9.55-35.87 \%$. The variance stabilizing transformation value ranged from $0.034-52.344 \%$. The variation contribution within the population was greater than the contribution among the population; the among-population rate was $2.864 \%$, while the within-population rate was $15.849 \%$; values of repeatability for among-population and within-population were 0.430 and 0.098 , respectively. This indicates that more variation arose from withinpopulation and that population repeatability was much greater than individual repeatability. Variation in the flower organ was greater than that in the leaf organ; this means that vegetative variation was more stable than reproductive variation. Variation in the southern population was greater than that in the northern population.
\end{abstract}

Key words: Magnolia sprengeri Pamp.; Population repeatability; Native habitat; Phenotypic diversity; Phenotypic variation 


\section{INTRODUCTION}

Magnolia sprengeri originated in China and belongs to the Magnolia family, which are deciduous, fragrant, and hysteranthous flowers appearing in March and early April. The plant is distributed in the forests and thickets of Chongqing, southern Gansu, Guizhou, southwestern Henan, Hubei, northwestern Hunan, northwestern Jiangxi (Xiushui), Shaanxi, central Sichuan, and the Yunnan mountain mountainous areas (Cui et al., 1964; Chen and Nooteboom, 1993; Liu et al., 1996; Chen, 1997; Ding, 1998; Fu, 2001; Figlar and Nooteboom, 2004; Lan et al., 2005). A very small number of live clones and herbarium specimens were introduced to the west approximately 100 years ago (Kang and Ejder, 2011).

As medicinal plants, the flower buds of $M$. biondii and the bark of $M$. officinalis are frequently harvested for traditional Chinese medicinal recipes. However, magnolia populations have been severely impacted by the rapid human population increase and subsequent gradual expansion of mountain agriculture to more marginal sites. Because of this over-exploitation, M. sprengeri has been listed as "Vulnerable" in the Red List of the Environmental Agency (Wang and Xie, 2004).

A widespread field investigation of $M$. sprengeri morphological variation was performed in 2008-2010. Further investigation was conducted in spring 2012. We grouped the plants into 2 populations based on morphological variation and geographical distribution (Kang and Ejder, 2011).

In this study, 2 natural populations of $M$. sprengeri distributed near the south and north Changjiang River were examined for phenotypic variation and diversity based on a large number of field surveys in order to reveal the basis of phenotypic variation in $M$. sprengeri, to study the genetic relationships between and within populations, and to provide scientific and theoretical bases for constructive protection strategies of $M$. sprengeri in their native habitats.

\section{MATERIAL AND METHODS}

\section{Investigation area and populations position}

M. sprengeri plants were divided into southern and northern populations according to the natural geographic division along the Yangtze River. The number of $M$. sprengeri in the southern population was larger than in the northern population. In this study, 30 single plants were selected randomly from each population, and 8 fully opened flowers in the spring and 30 mature leaves from normal growing branches in the autumn were investigated in each plant. Sample selection included the eastern, western, northern, and southern sections of each tree. Field investigation began in the Yangling Shaanxi Province, with the touring line shown in Figure 1, and was completed with the support of native residents and local forestry station staff members.

\section{Character selection and admeasurement}

Characters selected for analyses included those most frequently utilized in the keys and diagnoses of various taxa (Chen and Nooteboom, 1993; Liu et al., 1996; Figlar and Nooteboom, 2004). Thirty-seven morphological characters were selected from flowers and leaves (Table 1); the characters shown in Figure 2 were also observed. 


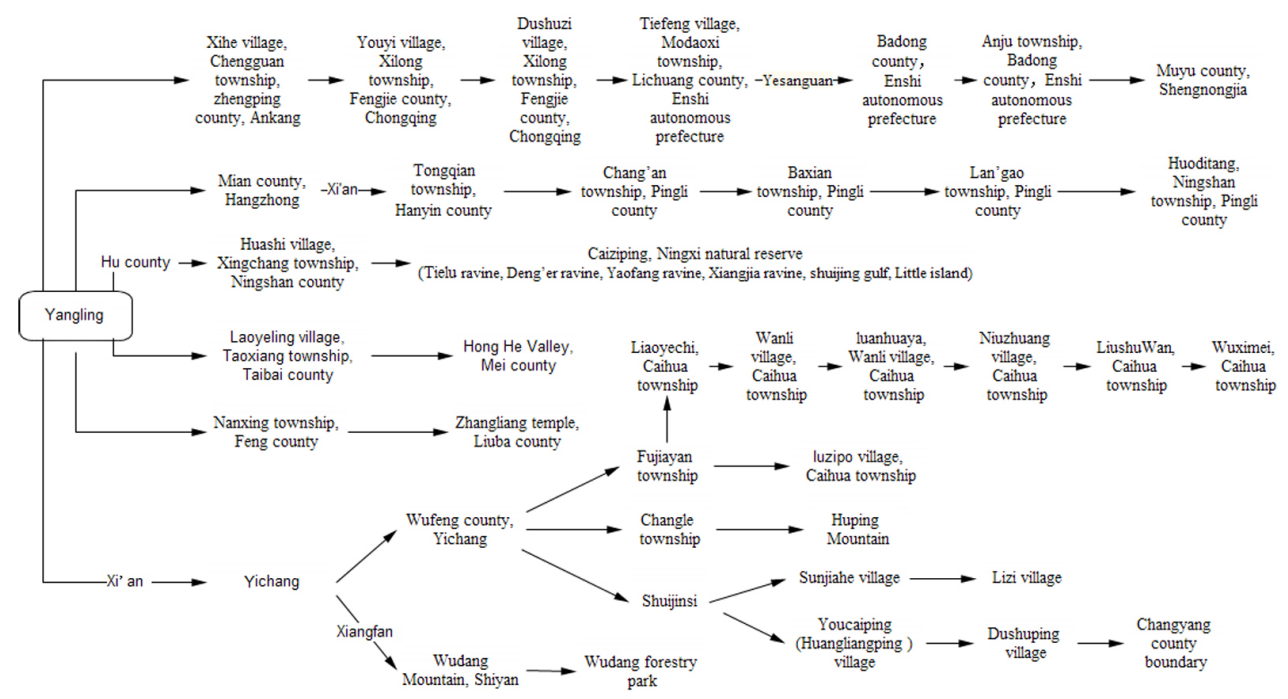

Figure 1. Touring line of field investigation of Magnolia sprengeri.

Table 1. Morphological characters evaluated in this study.

\begin{tabular}{|c|c|c|c|}
\hline Position & No. & Variable & Abbreviation \\
\hline Flower characters & $\begin{array}{r}1 \\
2 \\
3 \\
4 \\
5 \\
6 \\
7 \\
8 \\
9 \\
10 \\
11 \\
12 \\
13 \\
14 \\
15 \\
16 \\
17 \\
18 \\
19 \\
20 \\
21 \\
22 \\
23 \\
24 \\
25 \\
26 \\
27 \\
28 \\
29 \\
30 \\
31 \\
32 \\
33 \\
34 \\
35 \\
36 \\
37\end{array}$ & $\begin{array}{l}\text { Flower diameter } \\
\text { Flower height } \\
\text { Flower height/flower diameter } \\
\text { Stamen length } \\
\text { Filament length } \\
\text { Stamens No. } \\
\text { Filament length/stamen length } \\
\text { Pistil No. } \\
\text { Stamens No./pistil No. } \\
\text { Gynoecium length } \\
\text { Tepal No. } \\
\text { Gynoecium-androecium length } \\
\text { Stigma length } \\
\text { Carpel length } \\
\text { Receptacle } \\
\text { Tepal length } 1 \text { Whorl } \\
\text { Tepal width } 1 \text { Whorl } \\
\text { Tepal length/width } 1 \text { Whorl } \\
\text { Tepal length } 2 \text { Whorl } \\
\text { Tepal width } 2 \text { Whorl } \\
\text { Tepal length/width } 2 \text { Whorl } \\
\text { Tepal length } 3 \text { Whorl } \\
\text { Tepal width } 3 \text { Whorl } \\
\text { Tepal length/width } 3 \text { Whorl } \\
\text { Gynoecium width } \\
\text { Anther length } \\
\text { Anther length/stamen length } \\
\text { Leaf length } \\
\text { Leaf width } \\
\text { Leaf length/width } \\
\text { Leaf tip to widest length } \\
\text { Leaf lateral veins Nr } \\
\text { Petiole length } \\
\text { Leaf petiole width } \\
\text { Stipular scar length } \\
\text { Stipular scar length/width } \\
\text { Square root of leaf area } \\
\text { Thath }\end{array}$ & 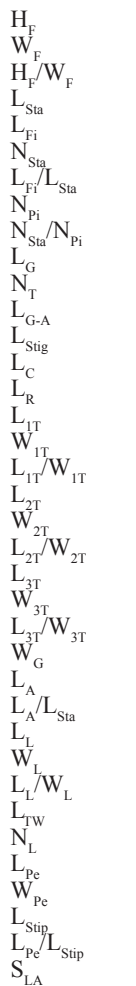 \\
\hline
\end{tabular}




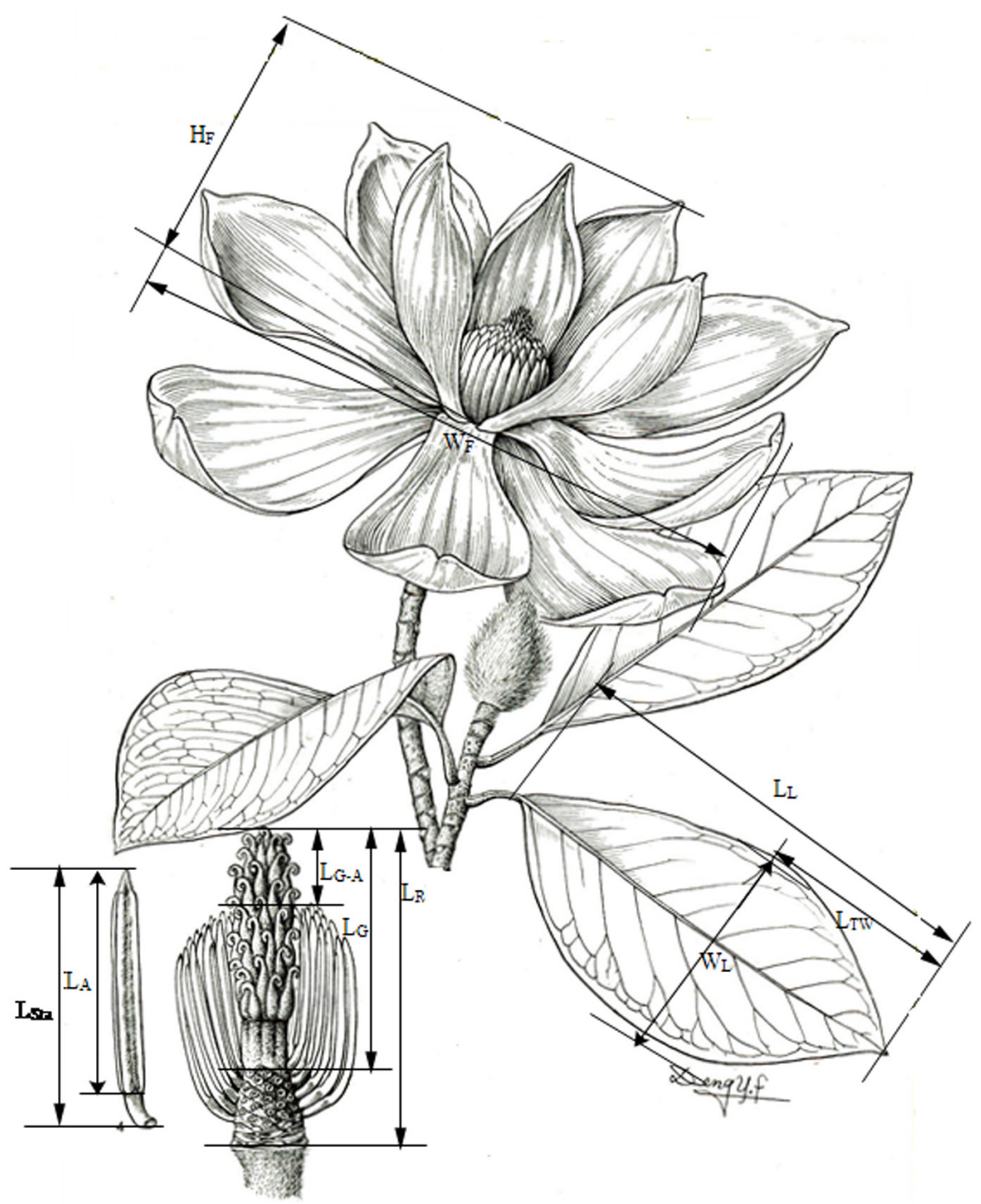

Figure 2. Character illustration of Magnolia sprengeri. For abbreviations, see Table 1.

Flower height, flower diameter, receptacle, tepal length, and width of $M$. sprengeri were measured using a ruler. The length of filament, stamen, gynoecium, stigma, carpel, and gynoecium-androecium and the width of the gynoecium was measured using calipers. Additionally, the number of androecium and pistils were counted using tweezers.

The length and width of the leaf and the distance from the tip to the widest part of the leaf were measured using a ruler. The length of the petiole and stipular scar was measured using calipers. Leaf area was measured using leaf area meter. In this study, the square root of the leaf area was measured rather than leaf area. The number of leaf lateral veins were also counted. 


\section{Statistical analysis}

\section{Character variation (Yang, 1981; Pei, 1991)}

Character mean values of each population were determined using:

$$
\overline{\mathrm{x}_{i}}=\frac{1}{n} \sum X_{i j}
$$

where $i$ is the population code, $j$ is the single plant code in the $i$ population.

Standard deviation values of characters in each population were determined using:

$$
S D_{i}=\sqrt{\frac{1}{n} \sum\left(X_{i j}-\overline{X_{i}}\right)^{2}}
$$

We used the variation coefficient $\left(C V_{i}\right)$ as the standard for determining the degree of phenotypic characters and the relative range $\left(R_{i}^{\prime}\right)$ to express the extreme variation degree of phenotypes within each population.

Character variation coefficient values for each population were determined as follows:

$$
C V_{i}=\frac{S D_{i}}{X_{i}}
$$

Relative range values of characters in each population were determined as follows:

$$
\begin{gathered}
R_{i}^{\prime}=\frac{R_{\mathrm{i}}}{R_{0}} \\
R_{i}=X_{i \text { max }}-X_{i \text { min }} \\
R_{0}=X_{i j \text { max }}-X_{i j \text { min }}
\end{gathered}
$$

\section{Nested analysis and phenotypic differentiation coefficient (Ge et al., 1988)}

The significance of the differences between populations and within populations was compared by nested analysis using the following linear model:

$$
Y_{i j k}=\mu+S_{i}+T_{(i) j}+\varepsilon_{i j k}
$$

(Equation 5) 
where $Y_{\mathrm{ijk}}$ is the $k$ replication observed in the $j$ single plant of the $i$ population, $\mu$ is the total mean value of samples, $S_{i}$ is the population effect, $T_{(i) j}$ is the single plant effect, and $\boldsymbol{E}_{\mathrm{ijk}}$ is the test error. The analysis was conducted using a general linear model with the SPSs software. Phenotypic differentiation degrees between populations were calculated using the phenotypic differentiation coefficient $\left(V_{\mathrm{ST}}\right)$ and the following formula:

$$
V_{S T}=\frac{\sigma_{t / s}^{2}}{\sigma_{t / s}^{2}+\sigma_{s}^{2}}
$$

where $\sigma_{t / s}^{2}$ is the mean variance value between populations and $\sigma_{s}^{2}$ is the mean variance value within populations.

\section{Repeatability (Ge et al., 1988)}

Repeatability $(R)$ reflects the repeatable stability of phenotypic diversity and can be used in germplasm utilization and selection breeding. The repeatability $(R)$ showed the continued degree of quantitative phenotypic characters for the same genetic organism under different time or different space conditions.

Population repeatability $\left(R_{P}\right)$ was calculated as follows:

$$
R_{P}=\frac{M S_{1}-M S_{2}}{M S_{1}+(P-1) M S_{2}}
$$

Individual repeatability $\left(R_{I}\right)$ was calculated as follows:

$$
R_{I}=\frac{M S_{2}-M S_{3}}{M S_{2}+(F-1) M S_{3}}
$$

where $M S_{1}$ is the mean square between populations for each character, $M S_{2}$ is the mean square within populations for each character for various characters, $M S_{3}$ is the mean square of the random error for each character, $P$ is the population number, and $F$ is the individual number.

SPSS 12.0 (SPSS Inc., Chicago, IL, USA) and Microsoft Excel softwares (2010) were used for statistical analyses.

\section{RESULTS}

\section{Morphological character variation trait}

\section{Character differences between populations}

The mean values for the differences in 37 characters between the southern and northern populations were analyzed using the $t$-test; the results are shown in Table 2 . 


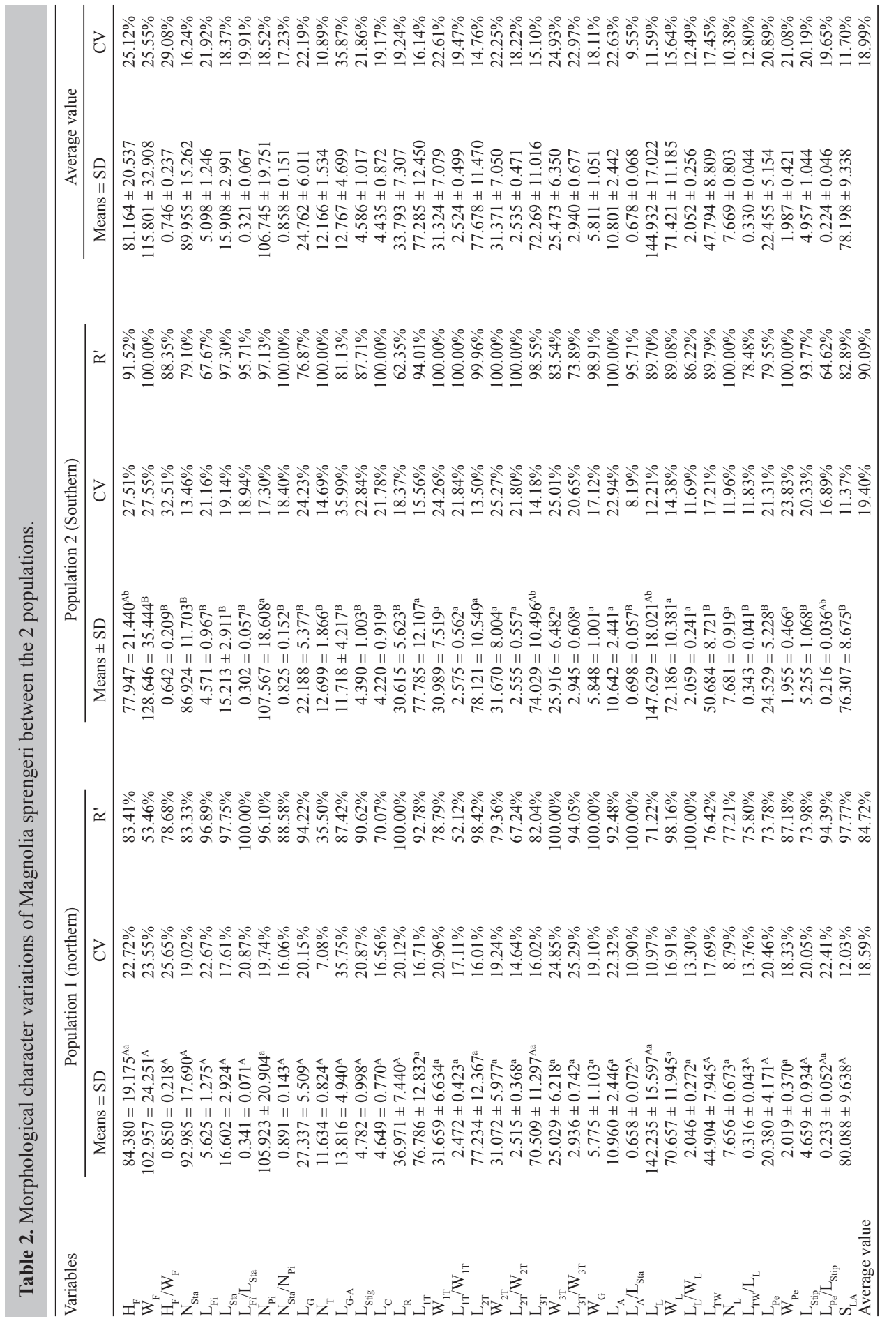


We observed that the mean values of $\mathrm{L}_{1 \mathrm{~T}}, \mathrm{~W}_{1 \mathrm{~T}}, \mathrm{~L}_{1 \mathrm{~T}} / \mathrm{W}_{1 \mathrm{~T}}, \mathrm{~L}_{2 \mathrm{~T}}, \mathrm{~W}_{2 \mathrm{~T}}$, and $\mathrm{L}_{2 \mathrm{~T}} / \mathrm{W}_{2 \mathrm{~T}}$ in the 2 populations were not significantly different. The mean values for $\mathrm{W}_{3 \mathrm{~T}}$ and $\mathrm{L}_{3 \mathrm{~T}} / \mathrm{W}_{3 \mathrm{~T}}$ in the 2 populations were not significantly different, but the mean value of $\mathrm{L}_{3 \mathrm{~T}}$ in the southern population was greater than that in the northern population for 0.05 levels. The ratio of tepal length to width revealed tepal shape in a certain degree. No significant differences were observed in the length, width, and shape of the tepal between the southern and northern populations in different whorls, except for $\mathrm{L}_{3 \mathrm{~T}}(\mathrm{P}>0.05)$.

$\mathrm{H}_{\mathrm{F}}$ and $\mathrm{W}_{\mathrm{F}}$ are the characters related to flower size, while the $\mathrm{H}_{\mathrm{F}} / \mathrm{W}_{\mathrm{F}}$ ratio is related to flower shape. The $\mathrm{W}_{\mathrm{F}}$ mean value of the southern population was greater than that of the northern population at the 0.01 level, while the $\mathrm{H}_{\mathrm{F}}$ mean value was the opposite, revealing that the unfolding degree of the southern population was greater than that of the northern population. We observed that the $\mathrm{H}_{\mathrm{F}} / \mathrm{W}_{\mathrm{F}}$ mean value of the southern population was greater than that of the northern population at the 0.05 level.

The mean value of $\mathrm{N}_{\mathrm{T}}$ for the south population was greater than that of the northern population at the 0.01 level, while the mean values of $\mathrm{N}_{\mathrm{Sta}}$ and $\mathrm{N}_{\mathrm{Sta}} / \mathrm{N}_{\mathrm{pi}}$ of the southern population were greater than those of the north population at the 0.01 level; $\mathrm{N}_{\mathrm{Pi}}$ in the 2 populations was not significantly different. According to the $\mathrm{ABC}(\mathrm{E})$ model of flower development, extra tepals are developed from primordia that normally develop into stamens (Kim et al., 2005; Kang and Ejder, 2011). This indicates that the number of tepals should increase, while the stamen number should decrease. However, our result showed that the mean values of $\mathrm{N}_{\mathrm{T}}$ and $\mathrm{N}_{\mathrm{Sta}}$ for the southern population were all greater than those of the northern population. This difference may have been caused by environmental factors; the proper temperature and rainfall conditions of southern population was favorable for the growth and development of M. sprengeri.

The mean values of $\mathrm{L}_{\mathrm{Fi}}, \mathrm{L}_{\mathrm{Sta}}, \mathrm{L}_{\mathrm{Fi}} / \mathrm{L}_{\mathrm{Sta}}, \mathrm{L}_{\mathrm{G}}, \mathrm{L}_{\mathrm{G}-\mathrm{A}}, \mathrm{L}_{\mathrm{Stig}}, \mathrm{L}_{\mathrm{C}}$, and $\mathrm{L}_{\mathrm{R}}$ of the southern population were greater than those of the northern population at the 0.01 level. This indicates that $M$. sprengeri in the southern population had better growth conditions than did the northern population.

The mean values of $\mathrm{L}_{\mathrm{TW}}, \mathrm{L}_{\mathrm{TW}} / \mathrm{L}_{\mathrm{L}}, \mathrm{L}_{\mathrm{Pe}}$, and $\mathrm{L}_{\mathrm{Stip}}$ in the southern population were greater than those in the northern population at the 0.01 level. $\mathrm{L}_{\mathrm{TW}}$ and $\mathrm{L}_{\mathrm{TW}} / \mathrm{L}_{\mathrm{L}}$ were related to the shape on leaf top, and leaves of the northern population were more blunt than those of the southern population. Petiole length and stipular scar length of the southern population were greater than those of the northern population. $\mathrm{L}_{\mathrm{L}}$ in southern population was greater at the 0.05 level, and $\mathrm{W}_{\mathrm{L}}$, $\mathrm{L}_{\mathrm{L}} / \mathrm{W}_{\mathrm{L}}$, and $\mathrm{N}_{\mathrm{L}}$ in the 2 populations were not significantly different, indicating no differences between the southern and northern populations with respect to leaf width, leaf shape, and leaf lateral veins (Nr). $\mathrm{S}_{\mathrm{LA}}$ in the southern population was less than that in the northern population at the 0.01 level. Leaf area was an important vegetative growth indicator, and the environment of the southern Changjiang River habitat was more suitable for M. sprengeri growth.

\section{Morphological character variations of Magnolia sprengeri between populations}

The coefficient of variation $(\mathrm{CV})$ is a normalized measurement for dispersion of the probability distribution. It is also known as the unitized risk or variation coefficient (Pei, 1991).

$C V$ values are shown in Table 1 . The mean value of $C V$ in the southern population was $19.40 \%$, which was greater than the $18.59 \%$ found in the northern population; the $C V$ mean value of flower characteristics in the southern population was $20.90 \%$, which was greater than in the northern population, showing a value of $19.69 \%$; the $C V$ mean value of leaf characters in the southern population was $15.73 \%$, which was less than the $15.88 \%$ observed in the northern 
population. In different organs, the $C V$ mean value of leaf characters was $15.28 \%$, which was less than the $20.71 \%$ observed for flower characters.

$\mathrm{L}_{\mathrm{G}-\mathrm{A}}$ was an important characteristic of species delimitation in Magnoliaceae (Liu et al., 1996). In our study examining $M$. sprengeri, the $C V$ values of $\mathrm{L}_{\mathrm{G}-\mathrm{A}}$ was greatest for all 37 characters. $\mathrm{H}_{\mathrm{F}} / \mathrm{W}_{\mathrm{F}}, \mathrm{W}_{\mathrm{F}}$, and $\mathrm{H}_{\mathrm{F}}$ are related with flower shape and size. The stability of flower shape and size-related characters was lower than other characters, and flower shape and size can be easily affected by external environmental factors, such as lower temperature, moisture, and soil nutrition, among other factors. The width of 3 whorl tepals $\left(\mathrm{W}_{3 \mathrm{~T}}, \mathrm{~W}_{1 \mathrm{~T}}\right.$, and $\left.\mathrm{W}_{2 \mathrm{~T}}\right)$ were greater than most characters, indicating that the width of the tepal is a relative variation character, similarly to $\mathrm{L}_{3 \mathrm{~T}} / \mathrm{W}_{3 \mathrm{~T}}$. The $C V$ of the $\mathrm{L}_{\mathrm{A}}$ value was also greater. $\mathrm{L}_{\mathrm{A}} / \mathrm{L}_{\mathrm{Sta}}$ was the lowest of all characters, and this character was more stable than the others; other similar flower-related characters were $\mathrm{N}_{\mathrm{T}}, \mathrm{L}_{3 \mathrm{~T}}$, and $\mathrm{L}_{2 \mathrm{~T}}$, indicating that the tepal number and length of the inner side the 2-whorl tepal were more stable.

For leaf characters, the $C V$ of $\mathrm{N}_{\mathrm{L}}$ was the lowest. In our study, $\mathrm{N}_{\mathrm{L}}$ mostly ranged from 7-9, and this character can be used to distinguish M. sprengeri from M. biondii (10-15) and M. campbellii (12-16), and discriminate M. sprengeri from M. dawsoniana (8-10), M. sargentiana (8-12), and $M$. denudata (8-10). However, the mean values of $\mathrm{N}_{\mathrm{L}}$ in the 2 populations were significantly different, and the $C V$ value of $\mathrm{N}_{\mathrm{L}}$ was lower, so $\mathrm{N}_{\mathrm{L}}$ is not a meaningful characteristic for studying variation within $M$. sprengeri species. The $C V$ of $\mathrm{W}_{\mathrm{L}}, \mathrm{L}_{\mathrm{TW}} / \mathrm{L}_{\mathrm{L}}, \mathrm{L}_{\mathrm{L}} /$ $\mathrm{W}_{\mathrm{L}}, \mathrm{S}_{\mathrm{LA}}$, and $\mathrm{L}_{\mathrm{L}}$ were relatively lower. These characters are indicative of leaf shape and size, and our results agree with former conclusions that the $C V$ mean value of flower characters was greater than that of leaf characters. Additionally, the stability of leaf characters was greater than that of flower characters.

$R_{i}^{\prime}$ was extremely valuable for each character, showing the following results: The mean value of $R_{i}^{\prime}$ in the southern population was $90.09 \%$, which was greater than the $84.72 \%$ observed in the northern population. The $R_{i}^{\prime}$ mean value of flower characters in the southern population was $88.32 \%$, which was greater than the $83.74 \%$ observed in the northern population. The $R_{i}^{\prime}$ mean value of leaf characters in the southern population was $91.86 \%$, which was greater than the $85.70 \%$ observed in the northern population. In different organs, the $R_{i}^{\prime}$ mean value of leaf characters was $86.03 \%$, which was lower than the $88.78 \%$ observed for flower characters.

\section{Nested analysis and phenotypic differentiation coefficient}

We used nested analysis to assay the genetic differentiation between and within populations for 37 characters. The results are shown in Table 3.

\section{Variance analysis}

Variances in 37 phenotypic traits within populations were all significant at the 0.01 levels, but variances between populations did not. For $\mathrm{H}_{\mathrm{F}}, \mathrm{H}_{\mathrm{F}} / \mathrm{W}_{\mathrm{F}}, \mathrm{L}_{\mathrm{Fi}}, \mathrm{L}_{\mathrm{G}}, \mathrm{N}_{\mathrm{T}}, \mathrm{L}_{\mathrm{R}}, \mathrm{L}_{\mathrm{A}} / \mathrm{L}_{\mathrm{Sta}}$, $\mathrm{L}_{\mathrm{TW}}, \mathrm{L}_{\mathrm{Pe}}$, and $\mathrm{W}_{\mathrm{Pe}}$, variances between populations were all significant at the 0.01 level, while $\mathrm{N}_{\text {Sta }}, \mathrm{L}_{\mathrm{Sta}}, \mathrm{L}_{\mathrm{Fi}} / \mathrm{L}_{\mathrm{Sta}}, \mathrm{L}_{\mathrm{C}}, \mathrm{N}_{\mathrm{L}}$, and $\mathrm{L}_{\text {Stip }}$ variances between populations were all significant at the 0.05 level. These characters were related to flower height and shape, stamen development, tepal number, leaf acuminate or truncation, leaf lateral veins $\mathrm{Nr}$, and petiole. Variances in $\mathrm{W}_{\mathrm{F}}$, $\mathrm{N}_{\mathrm{Pi}}, \mathrm{N}_{\mathrm{Sta}} / \mathrm{N}_{\mathrm{Pi}}, \mathrm{L}_{\mathrm{G}-\mathrm{A}}, \mathrm{L}_{\mathrm{Stig}}, \mathrm{W}_{\mathrm{G}}, \mathrm{L}_{\mathrm{A}}, \mathrm{L}_{\mathrm{L}}, \mathrm{W}_{\mathrm{L}}, \mathrm{L}_{\mathrm{L}} / \mathrm{W}_{\mathrm{L}}, \mathrm{L}_{\mathrm{Pe}}, \mathrm{L}_{\mathrm{Pe}} / \mathrm{L}_{\mathrm{Stip}}, \mathrm{S}_{\mathrm{LA}} \mathrm{L}_{1 \mathrm{~T}}, \mathrm{~W}_{1 \mathrm{~T}}, \mathrm{~L}_{1 \mathrm{~T}} / \mathrm{W}_{1 \mathrm{~T}}, \mathrm{~L}_{2 \mathrm{~T}}, \mathrm{~W}_{2 \mathrm{~T}}, \mathrm{~L}_{2 \mathrm{~T}} /$ 
$\mathrm{W}_{2 \mathrm{~T}}, \mathrm{~L}_{3 \mathrm{~T}}, \mathrm{~W}_{3 \mathrm{~T}}$, and $\mathrm{L}_{3 \mathrm{~T}} / \mathrm{W}_{3 \mathrm{~T}}$ between populations were not significant. These characters are mostly related to tepal size and shape, leaf size, and shape. Generally, phenotypic traits of $M$. sprengeri not only varied between populations, but also within populations; the individual phenotypic differences of $M$. sprenger $i$ were primarily affected by the hereditary basis within the population.

\begin{tabular}{|c|c|c|c|c|c|c|}
\hline \multirow{2}{*}{$\begin{array}{l}\text { Variables } \\
\mathrm{H}_{\mathrm{F}}\end{array}$} & \multicolumn{2}{|c|}{ Among regions } & \multicolumn{2}{|c|}{ Within regions } & \multicolumn{2}{|c|}{ Errors } \\
\hline & 1862,064 & (1) & 1131,592 & $(58)^{* *}$ & 66,685 & (120) \\
\hline & 29696.612 & $(1)^{* *}$ & 2633,300 & $(58)^{* *}$ & 95,155 & (120) \\
\hline $\mathrm{H}_{\mathrm{F}}^{\mathrm{F}} / \mathrm{W}_{\mathrm{F}}$ & 1,954 & $(1)^{* * *}$ & 0,131 & $(58)^{* *}$ & 0,004 & (120) \\
\hline $\mathrm{N}_{\mathrm{Sta}}^{\mathrm{F}}$ & 1652,980 & $(1)^{*}$ & 628,289 & $(58)^{* * *}$ & 30,001 & (120) \\
\hline $\mathrm{L}_{\mathrm{Fi}}^{\text {Sta }}$ & 49,988 & $(1)^{* *}$ & 3,215 & $(58)^{* *}$ & 0,347 & (120) \\
\hline $\mathrm{L}_{\mathrm{Si}}$ & 86,799 & $(1)^{*}$ & 16,320 & $(58)^{* *}$ & 4,738 & (120) \\
\hline $\mathrm{L}_{\mathrm{F}}^{\mathrm{Sa}} / \mathrm{L}_{\mathrm{Sta}}$ & 0,069 & $(1)^{*}$ & 0,010 & $(58)^{* * *}$ & 0,001 & (120) \\
\hline $\mathrm{N}_{\mathrm{pi}}^{\mathrm{ri}}$ & 121,633 & (1) & 106,795 & $(58)^{* * *}$ & 62,619 & (120) \\
\hline $\mathrm{N}_{\mathrm{St}}^{\mathrm{Pit}_{\mathrm{i}}} / \mathrm{N}_{\mathrm{pi}}$ & 0,200 & (1) & 0,063 & $(58)^{* *}$ & 0,002 & (120) \\
\hline $\mathrm{L}_{\mathrm{G}}$ & 1192,895 & $(1)^{* * *}$ & 59,662 & $(58)^{* *}$ & 15,116 & (120) \\
\hline $\mathrm{N}_{\mathrm{T}}$ & 51,053 & $(1)^{* * *}$ & 3,062 & $(58)^{* *}$ & 1,606 & (120) \\
\hline $\mathrm{L}_{\mathrm{G} .}^{\mathrm{T}}$ & 198,072 & (1) & 53,526 & $(58)^{* *}$ & 5,414 & (120) \\
\hline $\mathrm{L}_{\mathrm{S}-\mathrm{A}}$ & 6,927 & (1) & 2,461 & $(58)^{* *}$ & 0,295 & (120) \\
\hline $\mathrm{L}_{\mathrm{C}}^{\text {Stig }}$ & 8,282 & $(1)^{*}$ & 1,759 & $(58)^{* *}$ & 0,216 & (120) \\
\hline $\mathrm{L}_{\mathrm{R}}^{\mathrm{C}}$ & 908,972 & $(1)^{* * *}$ & 101,884 & $(58)^{* *}$ & 15,256 & (120) \\
\hline $\mathrm{L}_{\mathrm{R}}$ & 44,975 & (1) & 33,676 & $(58)^{* *}$ & 31,234 & (120) \\
\hline $\mathrm{W}_{1}$ & 20,221 & (1) & 18,075 & $(58)^{* * *}$ & 15,839 & (120) \\
\hline & 0,480 & (1) & 0,381 & $(58)^{* *}$ & 0,100 & (120) \\
\hline $\mathrm{L}_{2 \mathrm{~T}}$ & 35,431 & (1) & 32,203 & $(58)^{* *}$ & 25,394 & (120) \\
\hline $\mathrm{W}_{2}^{2 \mathrm{~T}}$ & 18,110 & (1) & 16,974 & $(58)^{* *}$ & 14,140 & (120) \\
\hline $\mathrm{L}_{2 \mathrm{~T}}{ }_{\mathrm{T}} / \mathrm{W}_{2 \mathrm{~T}}$ & 0,372 & (1) & 0,318 & $(58)^{* *}$ & 0,069 & (120) \\
\hline $\mathrm{L}_{3 \mathrm{~T}}^{21}$ & 557,515 & (1) & 317,292 & $(58)^{* *}$ & 23,009 & (120) \\
\hline $\mathrm{W}_{3}^{3 \mathrm{~T}}$ & 35,458 & (1) & 32,323 & $(58)^{* *}$ & 10,891 & (120) \\
\hline $\mathrm{L}_{3 \mathrm{~T}}{ }^{\mathrm{T}} \mathrm{W}_{3 \mathrm{~T}}$ & 0,639 & (1) & 0,598 & $(58)^{* *}$ & 0,102 & (120) \\
\hline $\mathrm{W}_{\mathrm{G}}$ & 0,640 & (1) & 0,541 & $(58)^{* *}$ & 0,434 & (120) \\
\hline $\mathrm{L}_{\mathrm{N}}$ & 5,153 & (1) & 4,718 & $(58)^{* *}$ & 3,243 & (120) \\
\hline $\mathrm{L}_{\mathrm{AN}}^{\mathrm{AN}} / \mathrm{L}_{\mathrm{Sta}}$ & 0,073 & $(1)^{* * *}$ & 0,010 & $(58)^{* *}$ & 0,001 & (120) \\
\hline & 1309,252 & (1) & 717,155 & $(58)^{* *}$ & 74,672 & (120) \\
\hline $\mathrm{W}_{\mathrm{t}}$ & 105,171 & (1) & 104,430 & $(58)^{* *}$ & 32,359 & (120) \\
\hline $\mathrm{L}_{\mathrm{L}}^{\mathrm{L}} / \mathrm{W}_{\mathrm{L}}$ & 0,208 & (1) & 0,167 & $(58)^{* *}$ & 0,017 & (120) \\
\hline $\mathrm{L}_{\mathrm{TW}}^{\mathrm{L}}$ & 1503,465 & $(1)^{* * *}$ & 166,216 & $(58)^{* * *}$ & 22,894 & (120) \\
\hline $\mathrm{N}_{\mathrm{t}}$ & 0,727 & $(1)^{*}$ & 0,638 & $(58)^{* *}$ & 0,237 & (120) \\
\hline $\mathrm{L}_{\mathrm{Lw}}^{\mathrm{L}} / \mathrm{L}_{\mathrm{L}}$ & 0,034 & $(1)^{* * *}$ & 0,004 & $(58)^{* *}$ & 0,001 & (120) \\
\hline $\mathrm{W}_{\mathrm{Pe}} \mathrm{L}$ & 774,602 & $(1)^{* * *}$ & 46,401 & $(58)^{* *}$ & 10,744 & (120) \\
\hline $\mathrm{L}_{\mathrm{Pc}}$ & 0,179 & (1) & 0,160 & $(58)^{* *}$ & 0,144 & (120) \\
\hline $\mathrm{L}_{\mathrm{Stit}}^{\mathrm{Te}}$ & 15,983 & $(1)^{*}$ & 2,481 & $(58)^{* *}$ & 0,295 & (120) \\
\hline $\mathrm{L}_{\mathrm{stip}}^{\mathrm{Stip}} / \mathrm{L}_{\mathrm{pe}}$ & 0,013 & (1) & 0,005 & $(58)^{* *}$ & 0,001 & (120) \\
\hline $\mathrm{is}_{\mathrm{S}}$ & 643,104 & (1) & 218,812 & $(58)^{* *}$ & 18,951 & (120) \\
\hline
\end{tabular}

*Represents significant differences at the 0.05 level $(\mathrm{P}<0.05)$, ${ }^{* *}$ represents significant differences at the 0.05 level $(\mathrm{P}<0.01)$.

\section{Phenotypic differentiation between populations}

The variance component and percent of each variance component are shown in Table 4. The variance component average value of 37 characters among the population was $2.864 \%$, within population was $15.849 \%$, and error was $81.286 \%$.

There were large differences in 37 characters; the range of the differentiation coefficient between populations for the 37 characters ranged from $0.034-52.344 \%$. The mean $V_{\text {ST }}$ value of the 37 characters was $12.501 \%$, indicating that the variation among populations was lower than the variation within populations. The mean $V_{\mathrm{ST}}$ value of flower organ characters was $12.672 \%$, while the mean $V_{\mathrm{ST}}$ value of flower organ characters was $11.288 \%$. This indicates that the variation between flower organs was greater than that between leaf organs. 


\section{Stability of phenotypic traits}

As shown in Table 4, the mean values of population repeatability and individual repeatability of the 37 phenotypic characters were 0.430 and 0.098 , respectively. The mean population repeatability and individual repeatability values for flower characters and leaf organ characters were $0.418,0.100$, and $0.462,0.090$, respectively. For both flower characters and leaf characters, population repeatability was greater than individual repeatability, indicating that the heredity of the population was higher than the heredity of the individual. The mean value of flower characters was lower than that of leaf characters for population repeatability, and the mean value of flower characters was greater than that of leaf characters for individual repeatability, but the difference was not significant. This result indicates that the stability of leaf organs was higher than that of flower organs on the population level; on an individual level, the stability of the leaf and flower was low. Leaf stability showed the lowest value.

\begin{tabular}{|c|c|c|c|c|c|c|c|c|c|}
\hline \multirow[t]{2}{*}{ Variables } & \multicolumn{3}{|c|}{ Variance component } & \multicolumn{3}{|c|}{ Percent of variance component } & \multirow{2}{*}{$\begin{array}{c}\text { Differentiation } \\
\text { coefficient }\end{array}$} & \multicolumn{2}{|c|}{ Repeatability } \\
\hline & $\delta_{t / \mathrm{s}}^{2}$ & $\delta_{t / s}^{2}$ & $\delta_{\mathrm{e}}^{2}$ & Among regions & Within region & Errors & & $\mathrm{R}_{\mathrm{p}}$ & $\mathrm{R}_{1}$ \\
\hline$\overline{\mathrm{H}_{\mathrm{F}}}$ & 0.812 & 35.497 & 66.685 & $0.788 \%$ & $34.465 \%$ & $64.747 \%$ & $2.235 \%$ & 0.244 & 0.210 \\
\hline $\mathrm{W}_{\mathrm{F}}$ & 30.070 & 84.605 & 95.155 & $14.331 \%$ & $40.321 \%$ & $45.349 \%$ & $26.222 \%$ & 0.837 & 0.308 \\
\hline $\mathrm{H}_{\mathrm{F}}^{\mathrm{F}} / \mathrm{W}_{\mathrm{F}}$ & 0.002 & 0.004 & 0.004 & $19.096 \%$ & $39.722 \%$ & $41.182 \%$ & $32.466 \%$ & 0.875 & 0.325 \\
\hline $\mathrm{N}_{\text {Sta }}^{\mathrm{F}}$ & 1.139 & 19.943 & 30.001 & $2.229 \%$ & $39.041 \%$ & $58.730 \%$ & $5.401 \%$ & 0.449 & 0.249 \\
\hline $\mathrm{L}_{\mathrm{Fi}}^{\text {Sta }}$ & 0.052 & 0.096 & 0.347 & $10.517 \%$ & $19.346 \%$ & $70.138 \%$ & $35.217 \%$ & 0.879 & 0.121 \\
\hline $\mathrm{L}_{\mathrm{Sta}}$ & 0.078 & 0.386 & 4.738 & $1.505 \%$ & $7.421 \%$ & $91.073 \%$ & $16.864 \%$ & 0.683 & 0.039 \\
\hline $\mathrm{L}_{\mathrm{Fi}}^{\mathrm{Sta}} / \mathrm{L}$ & 0.000 & 0.000 & 0.001 & $3.894 \%$ & $17.553 \%$ & $78.552 \%$ & $18.158 \%$ & 0.743 & 0.101 \\
\hline $\mathrm{N}_{\mathrm{Pi}}$ & 0.016 & 1.473 & 62.619 & $0.026 \%$ & $2.297 \%$ & $97.677 \%$ & $1.107 \%$ & 0.065 & 0.012 \\
\hline $\mathrm{N}_{\text {Sta }}^{\text {Pi }}$ & 0.000 & 0.002 & 0.002 & $3.679 \%$ & $48.762 \%$ & $47.559 \%$ & $7.016 \%$ & 0.523 & 0.339 \\
\hline $\mathrm{L}_{\mathrm{G}}^{\mathrm{Sta}}$ & 1.259 & 1.485 & 15.116 & $7.050 \%$ & $8.314 \%$ & $84.636 \%$ & $45.887 \%$ & 0.905 & 0.047 \\
\hline $\mathrm{N}_{\mathrm{T}}$ & 0.053 & 0.049 & 1.606 & $3.123 \%$ & $2.843 \%$ & $94.034 \%$ & $52.344 \%$ & 0.887 & 0.015 \\
\hline $\mathrm{L}_{\mathrm{G}-\mathrm{A}}^{\mathrm{T}}$ & 0.161 & 1.604 & 5.414 & $2.237 \%$ & $22.341 \%$ & $75.422 \%$ & $9.103 \%$ & 0.575 & 0.129 \\
\hline $\mathrm{L}_{\text {Stig }}^{-\mathrm{A}}$ & 0.005 & 0.072 & 0.295 & $1.334 \%$ & $19.419 \%$ & $79.247 \%$ & $6.428 \%$ & 0.476 & 0.109 \\
\hline $\mathrm{L}_{\mathrm{C}}^{\mathrm{stg}}$ & 0.007 & 0.051 & 0.216 & $2.639 \%$ & $18.719 \%$ & $78.642 \%$ & $12.355 \%$ & 0.650 & 0.106 \\
\hline $\mathrm{L}_{\mathrm{R}}^{\mathrm{C}}$ & 0.897 & 2.888 & 15.256 & $4.710 \%$ & $15.166 \%$ & $80.124 \%$ & $23.696 \%$ & 0.798 & 0.086 \\
\hline $\mathrm{L}_{1 \mathrm{~T}}^{\mathrm{R}}$ & 0.013 & 0.081 & 31.234 & $0.040 \%$ & $0.260 \%$ & $99.700 \%$ & $13.364 \%$ & 0.144 & 0.001 \\
\hline $\mathrm{W}_{1}$ & 0.002 & 0.075 & 15.839 & $0.015 \%$ & $0.468 \%$ & $99.517 \%$ & $3.100 \%$ & 0.056 & 0.002 \\
\hline $\mathrm{L}_{1 \mathrm{~T}}{ }^{11}$ & 0.000 & 0.009 & 0.100 & $0.101 \%$ & $8.548 \%$ & $91.351 \%$ & $1.163 \%$ & 0.115 & 0.045 \\
\hline $\mathrm{L}_{2 \mathrm{~T}}$ & 0.004 & 0.227 & 25.394 & $0.014 \%$ & $0.886 \%$ & $99.100 \%$ & $1.556 \%$ & 0.048 & 0.004 \\
\hline $\mathrm{W}_{2 T}^{2 T}$ & 0.001 & 0.094 & 14.140 & $0.009 \%$ & $0.663 \%$ & $99.328 \%$ & $1.319 \%$ & 0.032 & 0.003 \\
\hline $\mathrm{L}_{2 \mathrm{~T}}{ }^{2 \mathrm{~T}} / \mathrm{I}$ & 0.000 & 0.008 & 0.069 & $0.078 \%$ & $10.747 \%$ & $89.175 \%$ & $0.716 \%$ & 0.078 & 0.057 \\
\hline $\mathrm{L}_{3 \mathrm{~T}}^{2 \mathrm{~T}}$ & 0.267 & 9.809 & 23.009 & $0.807 \%$ & $29.649 \%$ & $69.544 \%$ & $2.649 \%$ & 0.275 & 0.176 \\
\hline $\mathrm{W}_{3 \mathrm{~T}}^{3 \mathrm{~T}}$ & 0.003 & 0.714 & 10.891 & $0.030 \%$ & $6.154 \%$ & $93.816 \%$ & $0.485 \%$ & 0.046 & 0.032 \\
\hline $\mathrm{L}_{3 \mathrm{~T}}^{3 \mathrm{~T}} / \mathrm{W}_{3 \mathrm{~T}}$ & 0.000 & 0.017 & 0.102 & $0.038 \%$ & $13.913 \%$ & $86.049 \%$ & $0.272 \%$ & 0.033 & 0.075 \\
\hline $\mathrm{W}_{\mathrm{G}}$ & 0.000 & 0.004 & 0.434 & $0.025 \%$ & $0.820 \%$ & $99.155 \%$ & $2.948 \%$ & 0.083 & 0.004 \\
\hline$L^{G}$ & 0.000 & 0.049 & 3.243 & $0.015 \%$ & $1.494 \%$ & $98.491 \%$ & $0.973 \%$ & 0.044 & 0.008 \\
\hline $\mathrm{L}_{\mathrm{AN}}^{\mathrm{AN}} / \mathrm{L}_{\mathrm{Sta}}$ & 0.000 & 0.000 & 0.001 & $4.102 \%$ & $17.378 \%$ & $78.519 \%$ & $19.098 \%$ & 0.755 & 0.100 \\
\hline $\mathrm{L}_{\mathrm{L}}$ & 0.658 & 21.416 & 74.672 & $0.680 \%$ & $22.136 \%$ & $77.184 \%$ & $2.980 \%$ & 0.292 & 0.125 \\
\hline $\mathrm{W}_{\mathrm{L}}^{\mathrm{L}}$ & 0.001 & 2.402 & 32.359 & $0.002 \%$ & $6.911 \%$ & $93.087 \%$ & $0.034 \%$ & 0.004 & 0.036 \\
\hline $\mathrm{L}_{\mathrm{L}} / \mathrm{W}_{\mathrm{L}}$ & 0.000 & 0.005 & 0.017 & $0.206 \%$ & $22.685 \%$ & $77.109 \%$ & $0.899 \%$ & 0.109 & 0.128 \\
\hline $\mathrm{L}_{\mathrm{TW}}^{\mathrm{L}}{ }^{\mathrm{L}}$ & 1.486 & 4.777 & 22.894 & $5.096 \%$ & $16.385 \%$ & $78.519 \%$ & $23.723 \%$ & 0.801 & 0.094 \\
\hline $\mathrm{N}_{\mathrm{L}}$ & 0.000 & 0.013 & 0.237 & $0.039 \%$ & $5.346 \%$ & $94.615 \%$ & $0.731 \%$ & 0.065 & 0.027 \\
\hline $\mathrm{L}_{\mathrm{TW}}^{\mathrm{L}} / \mathrm{L}_{\mathrm{L}}$ & 0.000 & 0.000 & 0.001 & $4.541 \%$ & $16.506 \%$ & $83.494 \%$ & $21.577 \%$ & 0.779 & 0.090 \\
\hline $\mathrm{L}_{\mathrm{Pe}}^{\mathrm{TW}}$ & 0.000 & 0.000 & 0.001 & $4.344 \%$ & $15.789 \%$ & $79.866 \%$ & $21.577 \%$ & 0.887 & 0.052 \\
\hline $\mathrm{W}_{\mathrm{pe}}^{\mathrm{Pe}}$ & 0.809 & 1.189 & 10.744 & $6.350 \%$ & $9.328 \%$ & $84.322 \%$ & $40.502 \%$ & 0.057 & 0.002 \\
\hline $\mathrm{L}_{\mathrm{se}}^{\mathrm{pe}}$ & 0.015 & 0.073 & 0.295 & $3.922 \%$ & $19.055 \%$ & $77.023 \%$ & $17.069 \%$ & 0.731 & 0.110 \\
\hline $\mathrm{L}_{\text {Stip }} / \mathrm{L}_{\mathrm{Pe}}$ & 0.000 & 0.000 & 0.001 & $1.104 \%$ & $16.541 \%$ & $82.355 \%$ & $6.255 \%$ & 0.462 & 0.091 \\
\hline $\mathrm{S}_{\mathrm{LA}}$ & 0.471 & 6.662 & 18.951 & $1.807 \%$ & $25.540 \%$ & $72.653 \%$ & $6.609 \%$ & 0.492 & 0.149 \\
\hline
\end{tabular}




\section{DISCUSSION}

Abundant variations were observed among populations and within populations of $M$. sprengeri. Variance analysis revealed that the variance in 37 phenotypic traits within populations were all significant, and that the variation was abundant among populations. The variation contribution within the population was greater than that among the population. The value of population repeatability was much greater than that of individual repeatability; phenotypic variation within the population was more abundant than that among the population. Thus, phenotypic traits among the population were more stable than phenotypic traits within the population.

While this difference was associated with the ecological environment, it was also related to genetic factors. The differences within the population were more dependent on genetic factors, and the differences between populations may be related to both. However, the existence of the differences is beneficial for choosing germplasm resources.

In the comparison of the $C V$ values for flower organ and leaf organ, the variation in the flower $(20.71 \%)$ was greater than that of the leaf $(15.28 \%)$. The $V_{\mathrm{ST}}$ value of flower organ characters was $12.672 \%$, while $V_{\mathrm{ST}}$ value of leaf organ characters was $11.288 \%$, indicating that variation in $M$. sprengeri for both leaf organ characters and flower organ characters were primarily caused by within-population factors. This result agrees with the variance component value results. Phenotypic differentiation of $M$. sprengeri organs underwent nonsynchronous evolution, and the phenotypic differentiation in the flower was greater than that in the leaf. Leaf organs were more stable than flower organs, which formed twist aggregate fruit, indicating that the vegetative organ was more stable than the reproductive organs.

The mean $C V$ values for the 37 phenotypic traits in the northern and southern populations of M. sprengeri were 18.59 and $19.40 \%$, respectively, indicating that the southern population variance was higher than that in the northern population and that the stability of northern population was greater than that of the south population.

The $C V$ of different phenotypic traits differed greatly. This indicates that the evolution of different characters occurred at nonsynchronous speeds in $M$. sprengeri. The $\mathrm{L}_{\mathrm{A}} / \mathrm{L}_{\text {Sta }}$ was the most stable inherited trait and the gynoecium-androecium length was the most variable inherited trait.

Large-scale phenotypic variations in plants are beneficial to populations. Phenotypic range is associated with various genotypes in populations. In our study, there was significant genetic differentiation both within and among the populations (Yang et al., 2014), enabling the M. sprengeri populations to adapt to various environmental conditions.

As indicated by the geographical distributions of $M$. sprengeri, there were large-scale discrete characters in each population. Because of the diversity and complexity of environmental factors in each population, different pressures contributing to natural selection and infrequent gene flow caused by geographic isolation led to abundant phenotypic variation in M. sprengeri.

Differentiation within populations was much higher than differentiation between populations. Therefore, for genetic resource protection and improvement, the native habitats should be protected appropriately and the valuable individuals should be ex situ conservation by selection and collection. Furthermore, protection of $M$. sprengeri should combine with usage. 
These results also agreed with our field investigation. The M. sprengeri showed abundant variation in the habitat. For example, the color of the flowers changed from white to red, which were categorized into 5 types in 2 groups according to tepal stipe and texture. The "white type" was generally found north of the ChangJiang (Yangtze River, which flows west to east and divides the main area of distribution in 2 halves) and the "red type" was found south of this natural divide; the tepal texture in the north was more freshy and tepal texture in the south was more crinkled. This categorization not only revealed phenotypic characteristics, but also reflected regional characteristics; however, intermediate cases were observed. For example, some $M$. sprengeri plants distributed in the southern population carried white flowers and crinkled tepals.

Phenotypic range was widely associated with difference in genotypes between the populations, enabling populations to adapt to different circumstances. $M$. sprengeri is a mountain plant that is able to adapt to different environments in 800-2100 m elevations (Chen and Nooteboom, 1993; Liu et al., 1996; Chen, 1997; Ding, 1998; Fu, 2001; Figlar and Nooteboom, 2004). M. sprengeri is mainly distributed in the climate transition zone, in which the terrain factors, climate factors, and other ecological factors were present. Through long-term geographical isolation and natural selection, abundant intraspecific variation and subpopulation variation developed. Phenotypic variation results from the interaction between genetic and environmental factors and is an important clue to genetic variation. Hence, phenotypic variation must have a genetic basis.

Therefore, the selection, protection, and utilization of M. sprengeri should be prioritized in strategies for collecting and utilizing these sources and more habitats of these populations should be protected. Thus, when considering specific variations of the populations for inbreeding, the collection and selection of parent plants must be done carefully.

\section{ACKNOWLEDGMENTS}

The staff members of a large number of forestry bureaus and forest farms were helpful and willing to share their knowledge and experiences. Research supported by the National Forestry Research and Special Public Service (\#201404302) and the Forestry Research and Special Public Service (\#200904004).

\section{REFERENCES}

Chen BL and Nooteboom HP (1993). Notes on Magnoliaceae III: The Magnoliaceae of China. Ann. MO Bot. Gard. 80: 999-1104

Chen HB (1997). Flora of Shandong Province. Vol. 2. Qingdao Publishing House, Shandong, 71-72.

Cui YW, Wang ZB, Fu KJ, Guo BZ, et al. (1964). Flora of Qinglin. Vol. 1. Science Press, Beijing, 338.

Ding BZ (1998). Flora of Henan. Vol. 4. Henan Science and Technology Press, Zhengzhou, 514.

Figlar RB and Nooteboom HP (2004). Notes on Magnoliaceae IV. Blumea-biodiversity, evolution and biogeography of plants. Nat. Herb. Netherlands 49: 87-100.

Fu SX (2001). Flora Hubeiensis. Vol. 1. Hubei Science and Technology Press, Wuhan, 427.

Ge S, Wang MX and Chen YW (1988). An analysis of population genetic structure of masson pine by isozyme technique. Sci. Silvae Sin. 24: 399-409.

Lan YS, Song K and An LZ (2005). Flora of Qinglin. Vol. 1. Gansu Science Press, Lanzhou.

Liu YH, Luo XR, Wu RF and Zhang BN (1996). Flora of China. Vol. 30. Science Press, Beijing.

Kang YX and Ejder E (2011). Magnolia sprengeri Pamp.: Morphological variation and geographical distribution. Plant Biosyst. 145: 906-923. 
Kim S, Koh J, Yoo M-J, Kong H, et al. (2005). Expression of floral MADS-box genes in basal angiosperms: Implications for the evolution of floral regulators. Plant J. 43: 724-744.

Pei XD (1991). Multivariate statistical analysis and application. Beijing Agricultural University Press, Beijing.

Wang S and Xie Y (2004). China Species Red List. Vol. 1 Red List. Higher Education Press, Beijing, 127.

Yang HX (1981). Numerical Classification Methods in Plant Ecology. Science Press, Beijing.

Yang M, Zhang M, Shi SG, Kang YX, et al. (2014). Analysis of genetic structure of Magnolia sprengeri populations based on ISSR markers. Sci. Silvae Sin. 50: 76-81. 